\title{
Elucidation of the thermal insulation in textile materials
}

\begin{abstract}
It is discussed in this paper the latest research and development on thermal insulation of textiles. The property of clothing thermal insulation provides average consumers with thermal balance between the body and the environment to some extent, when they are dressed, or in vehicular cabins, buildings and so on. Meanwhile, it also provides emergency service personnel with an additional workable environment in fully encapsulated impermeable personal protective equipment. There is a dilemma between thermal comfort and ergonomic comfort when we are seeking for suitable thermal insulation materials of clothing. Recent years have seen many efforts made on thermoregulation property of clothing with varied textile material or clothing structure, while thermal manikin test, clothing microclimate test, psychology evaluation, or simulation experiment is often employed in analysis to be closer to reality besides thermal insulation index. Consumers show great demand for sophisticated thermal insulation of textile materials, which has a direct effect on individuals' physiological and physical activities. Thus, thermal insulation textiles will surely embrace great innovations along with global changes in climate and environment in the near future.
\end{abstract}

Volume 2 Issue 4 - 2017

\author{
Wenyan Gu,' Suijiu Wu, ${ }^{2}$ Suying $\mathrm{Li}^{3}$ \\ 'Department of Nonwoven Material and Engineering, Nantong \\ University, China \\ ${ }^{2}$ Department of Textile Engineering, Nantong University, China \\ ${ }^{3}$ Department of Nonwoven Material and Engineering, Nantong \\ University, China
}
Correspondence: Wenyan Gu, College of Textile and Clothing Nantong University, Nantong City 226019, Jiangsu Province, China, Tel 865I3850I287I, Fax 865I3850I287I, Email gu.wy@ntu.edu.cn

Received: July 21, 2017 | Published: August II, 2017

Keywords: thermal, insulation, textile, microclimate, manikin, psychology, simulation

Abbreviations: $\mathrm{CBRN}$, chemical biological radiological and nuclear; PET, polyethylene terephthalate; PP, pre-production; PVA, poly vinyl alcohol; PTFE, poly tetra fluoro ethylene

\section{Introduction}

In pace with the increase in purchasing power, consumers show great demand for sophisticated textile production, processing, and preparation in the apparel and fashion market, which accordingly has stimulated research and development in apparel, textile and clothing industry. However, it is undoubtedly that thermal insulation of clothing, which is concerned with the fundamental properties of clothing, is always one of the most important aspects in both consumers' purchasing consideration and companies' ad awareness. ${ }^{1,2}$ The property of clothing thermal insulation provides average consumers with thermal balance to some extent between the body and the environment, such as clothing, vehicular cabins, buildings and so on. Meanwhile, it also provides emergency service personnel, who are "required to respond to chemical, biological, radiological and nuclear (CBRN) threats, with an additional level of protection in the form of fully encapsulated impermeable personal protective equipment". ${ }^{3}$ Thus, thermal insulation of textiles has a direct effect on individuals' physiological and physical activities on this planet.

\section{Discussion}

Researches on thermal comfort of clothing are conductive to its new process and good performance. Research in the late 1930s "showed a constant skin temperature of $33.8^{\circ} \mathrm{C}$ in environments from $25^{\circ} \mathrm{C}$ to $32^{\circ} \mathrm{C} "{ }^{4}$ In the zone from $28^{\circ} \mathrm{C}$ down to $23^{\circ} \mathrm{C}$, "the body cools without physiological restraint until onset of chill". ${ }^{4}$ And there is no visible sweating "in conditions of rest or light activity" in the zone between $28^{\circ} \mathrm{C}$ and $30^{\circ} \mathrm{C}$, which thus was termed as "the zone of pure vasomotor regulation". ${ }^{4}$ It was concluded that "indoor clothing stretches the neutral zone from 2 to 7 degrees, and with the addition of heavier clothing the lower temperature limit may be extended almost indefinitely". ${ }^{4}$ Heavier clothing seems helpful to maintain constant skin temperature, but would worsen cloth furnish comfort. Thus, this displays the dilemma between thermal comfort and ergonomic comfort when we are seeking for suitable thermal insulation materials of clothing. Recent years have seen many efforts made on thermoregulation property of clothing with varied textile material or clothing structure. For example, Iwona Frydrych ${ }^{5}$ and Wioletta Sybilska ${ }^{6}$ reported that the employment of thicker laminate contributed to the higher value of thermal resistance, hence better protection against the cold. Wenyan $\mathrm{Gu}^{7}$ evaluated thermal resistance of melt spun thermal material with different thickness, and got the same result as that of the former. Patrick Kinnicutt ${ }^{8}$ compared a 3D textured knitting shirt with a non-3D textured knitting shirt. Those knitting shirts were worn next to the wearers' skin in hot and cold conditions respectively, and thermal images of wearers were taken. It was indicated that a 3D textured knitting shirt would be superior to non-3D textured knitting shirt in thermal insulation performance. As shown in Figure $1,{ }^{8}$ with regard to the property of thermal insulation, the difference between a 3D textured knitting shirt and a non-3D one is similar to the difference between a thicker shirt and a thick one. In this way, the conclusion is in agreement with the previous.

However, thermal insulation property of textile materials cannot be only optimized by arranging internal structures of such materials. Many environmental and personal factors also play an important part. So mathematical models ${ }^{9-12}$ were set up, considering not only personal factors, which include activity level and clothing insulation, but also environmental factors, such as air temperature, air velocity, radiant temperature and relative humidity. Therefore, the heat and transfer in textiles was displayed, the textile structure was optimized, and 
clothing insulation inside a vehicular cabin was estimated as shown in Table $1,{ }^{11}$ as well as in a building.

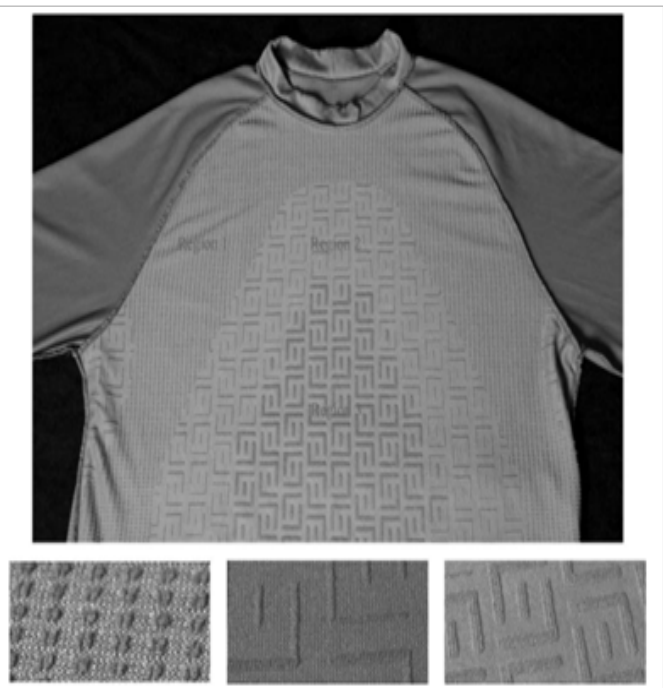

Figure I Image of the 3D textured knitting shirt's front, with full 3D texture mapping. The back of the garment is mapped identically to the front. ${ }^{8}$

Table I Clothing Levels and Insulation. ${ }^{10}$

\begin{tabular}{ll}
\hline Description & $\begin{array}{l}\text { Thermal insulation } \\
\text { range(Clo) }\end{array}$ \\
\hline Winter outdoor clothing & $3-\mathrm{Feb}$ \\
Normal indoor clothing & $\mathrm{I} .2-\mathrm{I} .5$ \\
Summer indoor clothing & $0.8-\mathrm{I} .2$ \\
Indoor "Lightweight" clothing & $0.3-0.5$ \\
\hline
\end{tabular}

Temperature was found to have an effect on the frequency of accidents as early as the beginning of 19 th century. ${ }^{13}$ Activity at extreme temperatures is more dangerous than the same activity at moderate temperature. So the research on thermal protective performances of textiles used under extreme temperature conditions is reasonable and meaningful. Chao $\mathrm{Sun}^{14}$ carried out a sweating fabric manikin experiment on multilayer textiles against low temperatures to varify the textiles with good thermo insulation performance. The multilayer textiles used PET batting as basic layers, and PA net, PP web, PP/PVA and nano-fibrous PP/PVA/AL were used for interlayer respectively. It was found that PP/PVA/AL inter layers were helpful to improve the cold protective performance of multilayer textiles. Shinjung Yoo ${ }^{15}$ conducted a human physiological study on a multilayer textile in low temperature, and verified that condensation in textile could be reduced by the structure of a layer. Thus, the appropriate layer structure should be adopted in the clothing design for low temperatures. VL Richmond ${ }^{3}$ recruited persons from firefighters, policeman, and military personnel. They wore as many their personal protective devices as the ones they should wear when they fulfilled their duties. He monitored their insulated skin temperature in personal protective devices at the temperature of $18^{\circ} \mathrm{C}$ and $30^{\circ} \mathrm{C}$ respectively. With experimental data and statistics analysis, it was declared that a rectal temperature in extreme conditions could be predicted in a curvilinear model. Hualing $\mathrm{He}^{16}$ selected 2 kinds of high performance thermal protective multilayer textiles from the extensive commercial applied thermal protective textiles in Industry, Fire and Rescue, etc. Such materials are often facing thermal hazards, so the moisture and the air in layers affect their thermal protective performance. The structure of the 2 multilayer textiles consisted of out shell (m-aramid twill), moisture barrier (para-aramid water thorn+PTFE), and thermal liner (para-aramid needling+cotton woven), and they were similar in both thickness and weight. He "simulated second-degree burn time for the two fabric assemblies under discrete specific moisture levels". ${ }^{16}$ It was shown that the air entrapped in multilayer textiles was positively effective on thermal protective textiles, but the air transport would cause changes.

\section{Conclusion}

In the research of thermal insulation of textiles, the influence of the microclimate between clothing and the body or the climate around the body, on insulation performance tends not to be ignored. As a result, the thermal manikin test, clothing microclimate test, psychology evaluation, or simulation experiment is often employed in analysis to be closer to reality besides thermal insulation index.

It is obvious that thermal insulation textiles have immense potential because they can be applied in individual functional thermal protection clothing and household stuffs as well as protective clothing under extreme temperature climate conditions. Thermal insulation textiles will surely embrace great innovations along with global changes in climate and environment in the near future.

\section{Acknowledgements}

This research was supported by Production, Practical, Experience and Research of Prospective Joint Research Projects of Jiangsu Province (BY2016203).

\section{Conflict of interest}

Author declares there is no conflict of interest.

\section{References}

1. https://www.3m.com/

2. http://www.gore-tex.com.cn/

3. Richmond VL, Wilkinson DM, Blacker SD, et al. Insulated skin temperature as a measure of core body temperature for individuals wearing CBRN protective clothing. Physiol Meas. 2013;34(11):1531-1543.

4. Hardy JD. The physical laws of heat loss from the human. Proc Natl Acad Sci USA. 1937;23(12):631-637.

5. Frydrych I, Wioletta S, Wajszczyk M. Analysis of selected physical properties of membrane fabrics influencing the utility comfort of clothing. Fibers text east eur. 2009;17(6):50-56.

6. Sybilska W, Korycki R. Analysis of thermal-insulating parameters in two- and three-layer textiles. Fibers text east eur. 2016;24(5):80-87.

7. Gu WY, Yang R, Dai ZJ, et al. Properties of thin and light garment thermal insulation materials. $J$ Nantong University (Natural science edition). 2012;11(2):57-61.

8. Kinnicutt P, Domina T, MacGillivray M, et al. Knit-in 3D mapping's effect on thermoregulation preliminary results. J Text I. 2015;101(2):120-127.

9. Hao JH, Chen Q, Hu K. Porosity distribution optimization of insulation materials by the variational method. Int J Heat Mass Tran. 2016;92:1-7.

10. Fontana É, Donca R, Mancusi E, et al. Mathematical modeling and numerical simulation of heat and moisture transfer in a porous textile medium. J Text I. 2016;107(5):672-682. 
11. Alahmer A, Omar MA, Mayyas A, et al. Effect of relative humidity and temperature control on in-cabin thermal comfort state. Appl Therm Eng. 2011;31(14-15):2636-2644.

12. Lee KH, Schiavon S. Influence of three dynamic predictive clothing insulation models on building energy use, HVAC sizing and thermal comfort. Energies. 2014;7(4):1917-1934.

13. Osborne E, Vernon H. The influence of temperature and other conditions on the frequency of industrial accidents. Her Majesty's Stationary Office, London; 1922.
14. Sun $\mathrm{C}$, Fan JT, Wu HJ, et al. Cold protective clothing with reflective nano-fibrous inter layers for improved comfort. Int J Cloth Sci Tech. 2013;25(5):380-388.

15. Yoo S, Kim E. Wear trial assessment of layer structure effects on vapor permeability and condensation in a cold weather clothing ensemble. Text Res J. 2012;82(11):1079-1091.

16. He HL, Yu ZC, Song GW. The effect of moisture and air gap on the thermal protective performance of fabric assemblies used by wildland firefighters. J Text I. 2016;107(8):1030-1036. 